\title{
Tubular versus stereotactic evacuation of medium- to large-sized supratentorial spontaneous intra cerebral hematoma
}

\author{
Mohamed A. Eshra®D
}

\begin{abstract}
Objective: Primary intracerebral hemorrhage due to hypertension or amyloid angiopathy is a major catastrophe to the brain especially in old age. It forms $20-30 \%$ of all strokes. Open craniotomy for evacuation of the hematoma may not be applicable in some patients with uncontrolled blood pressure and bad general conditions that do not permit general anesthesia. This study investigated the safety and efficacy of two minimally invasive procedures in the evacuation of spontaneous hypertensive medium to large intracerebral hematomas.
\end{abstract}

Patients and methods: This is a retrospective study during the period from June 2008 to December 2016; 36 patients suffering from hypertensive intracerebral hematoma were investigated, operated upon, and followed up for at least 1 year. The hematomas were evacuated by CT-guided stereotactic procedures in 18 patients and by microscopic assisted tubular approach in the other 18 patients. The age of patients ranged from 48 to 79 years. There were 26 males and 10 females included in the study. GCS on presentation was 8-13.

Results: In patients of the tubular group (15 males +3 females), the total mortality was 4 patients and 14 patients experienced different degrees of improvement: 3 patients were conscious with no deficits and good recovery, 9 patients were conscious with mild disability, and 2 patients were conscious with severe disability. The final results in patients ( 11 males +7 females) managed by stereotactic resection and thrombolysis of the hematoma after the follow-up period were as follows: 5 patients died, 1 patient was conscious with severe disability, 10 patients were conscious with mild disability, and 2 patients were conscious with complete recovery.

Conclusions: Minimally invasive hematoma resection procedures have advantages of reducing time and amount of surgical stress, the possibility of doing them under local anesthesia, facility of earlier evacuation, and reduced tissue trauma. Performing the procedures under image monitoring may be helpful in anticipating and detecting intraoperative accidents. Stereotactic aspiration is still helpful in chronic stage, where the clot becomes liquefied and easy for simple aspiration. This makes rehabilitation easier and further deterioration avoidable.

Keywords: Intracerebral hematoma, Stereotactic evacuation, Tubular evacuation

\section{Introduction}

Primary intracerebral hemorrhage due to hypertension or amyloid angiopathy is a major catastrophe to the brain especially in old age. It forms $20-30 \%$ of all strokes. The brain may be affected by sequelae of increased intracranial pressure or secondary damage by toxic by-products of hemoglobin degradation. There are many studies that outlined the different treatment

Correspondence: alatoolneuro@gmail.com

Department of Neurosurgery, Faculty of Medicine, Alexandria University,

Champillion St., Elazaritta, Alexandria, Egypt modalities and compared between the conservative management and surgical evacuation of the resulting hematoma. Roughly, the patients may get benefit from evacuation especially if the hematoma is large and surfacing. Open craniotomy for evacuation of the hematoma may not be applicable in some patients with uncontrolled blood pressure and bad general conditions that do not permit for general anesthesia [1-6]. Recently, the advances in minimally invasive procedures give a higher chance to treat such people earlier with 
Table 1 Summary of clinical presentations of tubular group

\begin{tabular}{|c|c|c|c|c|c|c|c|c|c|c|}
\hline & Age/sex & $\begin{array}{l}\text { History of } \\
\text { hypertension }\end{array}$ & Co-morbidities & GCS & Hemiparesis & Dysphasia & $\begin{array}{l}\text { Prothrombin activity } \\
\%\end{array}$ & $\begin{array}{l}\text { Site of } \\
\text { hematoma }\end{array}$ & $\begin{array}{l}\text { Size of hematoma } \\
\text { CM }\end{array}$ & Fate \\
\hline 1 & 64/male & + & Diabetes & 9 & + & - & 60 & Basal ganglia & 53 & Recovery \\
\hline 2 & 70/male & + & $\begin{array}{l}\text { Diabetes+ renal } \\
\text { failure }\end{array}$ & 10 & + & + & 52 & Basal ganglia & 46 & Died \\
\hline 3 & 57/female & + & & 12 & + & - & 74 & Subcortical & 35 & Recovery \\
\hline 4 & 68/male & + & Diabetes & 11 & + & + & 65 & Basal ganglia & 41 & Recovery \\
\hline 5 & $52 /$ male & - & & 13 & - & - & 80 & Basal ganglia & 33 & Recovery \\
\hline 6 & 58/male & + & & 11 & + & - & 75 & Subcortical & 38 & Recovery \\
\hline 7 & 61/male & + & & 10 & + & - & 67 & Subcortical & 48 & Recovery \\
\hline 8 & 63/female & + & Diabetes & 9 & + & + & 73 & Subcortical & 60 & Died \\
\hline 9 & 74/male & + & $\begin{array}{l}\text { Diabetes+ liver } \\
\text { cirrhosis }\end{array}$ & 8 & + & + & 46 & Basal ganglia & 64 & Died \\
\hline 10 & $57 /$ male & + & Diabetes & 12 & - & - & 54 & Basal ganglia & 39 & Recovery \\
\hline 11 & $\begin{array}{l}55 / \\
\text { female }\end{array}$ & + & & 11 & + & - & 66 & Basal ganglia & 43 & Recovery \\
\hline 12 & 60/male & + & & 10 & + & - & 78 & Basal ganglia & 42 & Recovery \\
\hline 13 & 50/male & + & & 12 & + & - & 86 & Subcortical & 36 & Recovery \\
\hline 14 & 61/male & + & Diabetes & 9 & + & + & 77 & Basal ganglia & 55 & Recovery \\
\hline 15 & 63/male & + & Diabetes & 10 & + & + & 63 & Subcortical & 51 & Recovery \\
\hline 16 & $56 /$ male & - & & 11 & + & - & 78 & Subcortical & 47 & Recovery \\
\hline 17 & 53/male- & + & & 12 & + & - & 81 & Basal ganglia & 40 & Recovery \\
\hline 18 & $67 /$ male & + & Diabetes & 9 & + & - & 51 & Basal ganglia & 65 & Died \\
\hline
\end{tabular}

Table 2 Summary of clinical presentations of stereotactic group

\begin{tabular}{|c|c|c|c|c|c|c|c|c|c|c|}
\hline & Age/sex & History of hypertension & Co-morbidities & GCS & Hemiparesis & Dysphasia & Prothrombin activity \% & Site of hematoma & Size of hematoma CM & Fate \\
\hline 1 & 56/female & + & & 12 & + & - & 56 & Basal ganglia & 41 & Recovery \\
\hline 2 & 70/male & + & Diabetic & 10 & + & - & 62 & Basal ganglia & 37 & Recovery \\
\hline 3 & 49/male & + & Renal failure & 8 & + & + & 45 & Basal ganglia & 59 & Died \\
\hline 4 & 61/female & + & $\begin{array}{l}\text { Diabetic } \\
\text { Hepatitis - C }\end{array}$ & 9 & + & - & 51 & Basal ganglia & 67 & Died \\
\hline 5 & 59/male & + & & 12 & - & - & 66 & Basal ganglia & 33 & Recovery \\
\hline 6 & 63/male & + & & 11 & + & - & 59 & Basal ganglia & 38 & Recovery \\
\hline 7 & 55/female & - & Hepatitis & 9 & + & + & 37 & Basal ganglia & 68 & Died \\
\hline 8 & $67 /$ male & + & & 12 & + & - & 66 & Basal ganglia & 40 & Recovery \\
\hline 9 & 70/female & + & & 10 & + & + & 54 & Basal ganglia & 42 & Recovery \\
\hline 10 & $54 /$ male & + & Diabetic & 11 & + & - & 56 & Basal ganglia & 35 & Recovery \\
\hline 11 & $68 /$ male & + & & 9 & + & + & 43 & Basal ganglia & 57 & Died \\
\hline 12 & 58/female & + & & 9 & + & - & 47 & Basal ganglia & 70 & Recovery \\
\hline 13 & 65/female & + & & 11 & + & - & 56 & Basal ganglia & 44 & Recovery \\
\hline 14 & $55 /$ male & - & Diabetic & 9 & + & - & 45 & Basal ganglia & 59 & Recovery \\
\hline 15 & 70/male & + & Diabetic & 8 & + & + & 30 & Basal ganglia & 69 & Recovery \\
\hline 16 & $59 / \mathrm{male}$ & + & & 12 & - & - & 68 & Basal ganglia & 32 & Recovery \\
\hline 17 & 53/female & + & Renal failure & 8 & + & + & 51 & Basal ganglia & 66 & Died \\
\hline 18 & $67 /$ male & + & Diabetic & 11 & + & - & 58 & Basal ganglia & 34 & Recovery \\
\hline
\end{tabular}




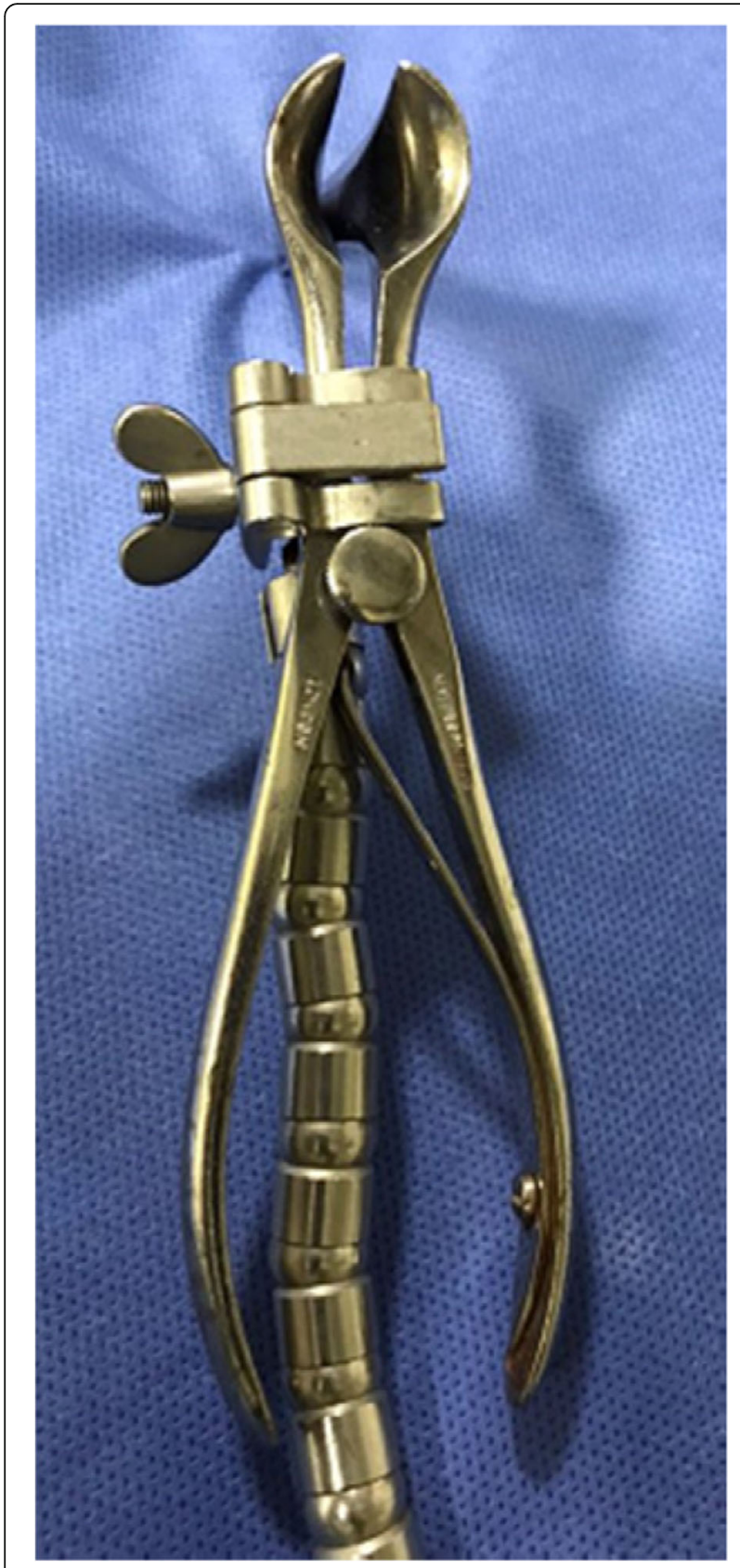

Fig. 1 Modified tubular retractor attached to external fixator

minimal risk under local anesthesia with decreased operative time and diminished blood loss [7, 8].

In this study, we tried to investigate the safety and efficacy of two minimally invasive procedures in the evacuation of spontaneous hypertensive medium to large supratentorial intracerebral hematomas.

\section{Methods}

This is a retrospective study during the period from June 2008 to December 2016; 36 patients suffering from hypertensive intracerebral hematoma were investigated,

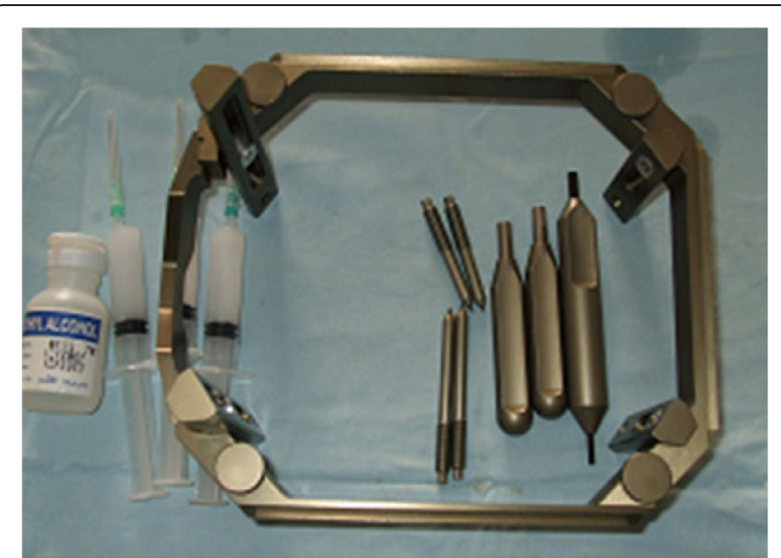

Fig. 2 The stereotaxy frame

operated upon, and followed up for at least 1 year. The hematomas were evacuated by CT-guided stereotactic procedures in 18 patients and by microscopic assisted tubular approach in the other 18 patients. The age of patients ranged from 48 to 79 years. There were 26 males and 10 females included in the study. Glasgow Coma Scale (GCS) on presentation was 8-13. Summary of clinical presentations of tubular and stereotactic groups was demonstrated in Tables 1and 2 respectively.

\section{Microscopic assisted tubular evacuation}

Under local anesthesia, with sedations, patient was put in supine position and small linear scalp incision was done localized over the center of the hematoma. Burr hole followed by localized craniectomy were done. The craniectomy widened the burr hole to be $2.5 \mathrm{~cm}$ in diameter. We opened the dura in a cruciate pattern, then bipolar cautery of the cortex was done. Brain cannula was inserted deep till the center of the hematoma trying to aspirate any fluid content. By the help of narrow brain spatula, we inserted the modified tubular retractor (Fig. 1), which was attached to external fixator that was tightened to keep the tubular retractor in place. The surgical microscope was used in all cases to

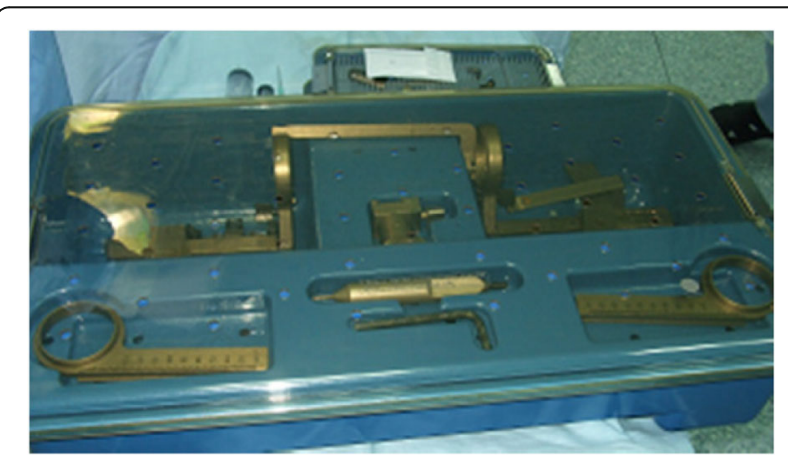

Fig. 3 Stereotaxy arc 


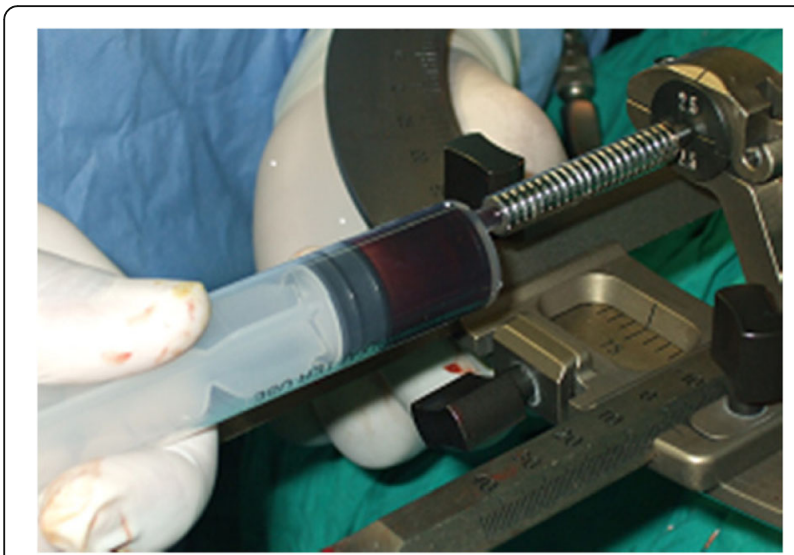

Fig. 4 Biopsy needle

visualize the surgical field. Through irrigation, gentle dissection, changing the angulation of the retractor, and aspiration, the hematoma was removed in a piecemeal manner. After the desired volume of the hematoma was resected, we removed the retractor and inspected the cortical tract for any bleeding which could be easily controlled. The aim of this method was removal of $50-75 \%$ of the hematoma size. When our aim was achieved, we abort the procedure with thorough washing of the core of the hematoma. After approximation of the dura, tight closure of the skin was done.

\section{CT-guided stereotactic aspiration and thrombolysis}

Under local scalp infiltration with lidocaine 1\%, the four screws of the stereotaxy frame (Leksell frame by Electa, Kungstensgatan 18, SE-103 93 Stockholm, Sweden) were applied to four points in the scalp (two frontal and two occipital) to fix the frame to the skull (Fig. 2). Care was taken to ensure the frame to be in level inferior to the site of the hematoma to guarantee containment of the clot within the dimensions of the frame.

In the CT suite, we obtained a CT scan with the stereotaxy frame applied to the head. We calculated the co-ordinates of one or more points in the clot mass. $X$, $Y$, and $Z$ values were obtained according to the formula specific to the frame manual.

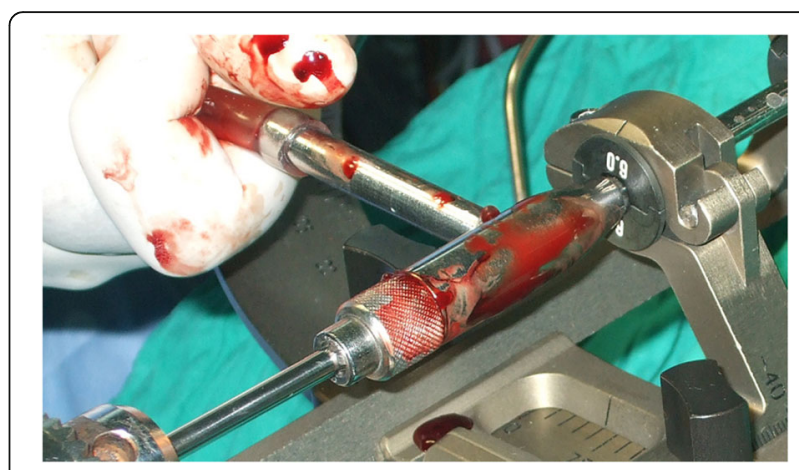

Fig. 6 Archimedes screw

In the operating room, the arc (Fig. 3) was applied and adjusted under sterile technique. Under local anesthesia, a linear skin incision, burr hole opening, and incision of the dura were done and these were followed by introduction of biopsy needle (Fig. 4) to the calculated target point for aspiration of the liquid component of the hematoma. Archimedes screw (Figs. 5 and 6) was then introduced for aspiration of the clotted part of the hematoma by suction and rotation of the screw. This was followed by insertion of a drainage catheter with exit from the scalp. Closure of the wound was done after fixation and connection of the catheter to a closed sterile drainage system.

Immediate post-operative CT confirmed intra-hematoma position of the draining catheter in all cases (Figs. 7, 8, 9, 10, 11, and 12). Subdural air was also found. A period of $36 \mathrm{~h}$ of gravitational catheter drainage was permitted.

In the second day in the neurosurgical unit, if needed, installation of urokinase (5000 IU, every $6-8 \mathrm{~h}$ for 48 $72 \mathrm{~h}$ ) and suction were amenable to be applied, unless contraindicated, and would be guided by repeated follow-up CT scans for determination of the volume of residual hematoma. This was to be done under sterile technique with cover of prophylactic antibiotics and monitoring of the patient coagulation profile. Removal of the catheter was done after reaching residual volume of $25 \mathrm{~mL}$ or less, or by the end of the post-operative $72 \mathrm{~h}$.

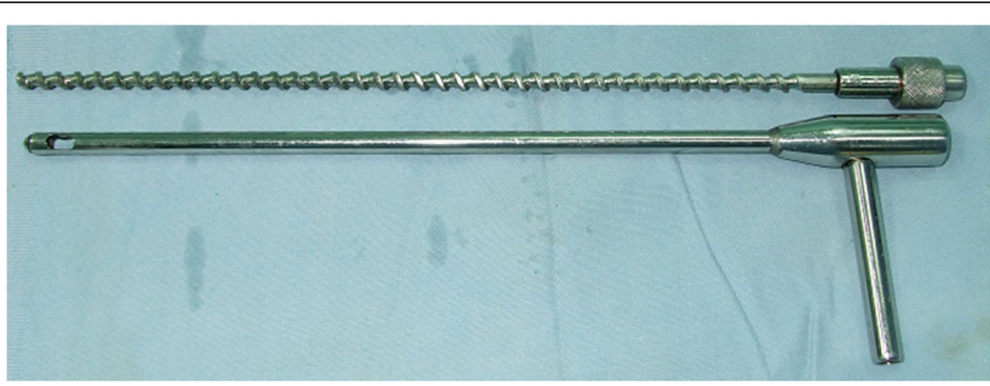

Fig. 5 Archimedes screw 


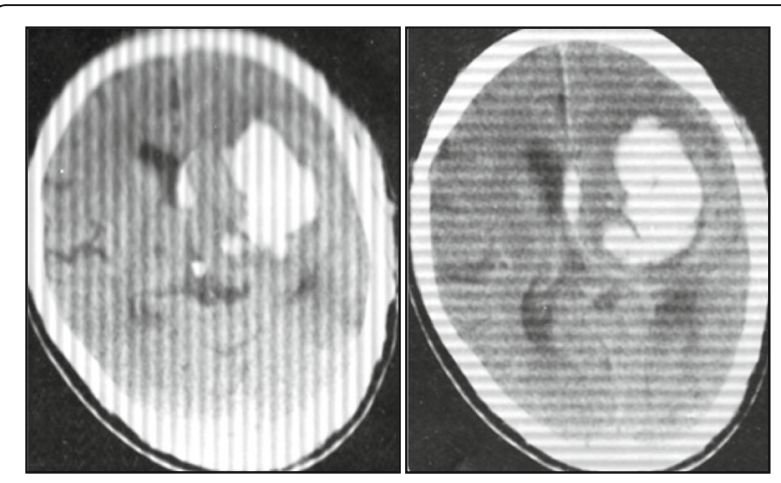

Fig. 7 CT admission of a case of intracerebral hematoma

\section{Results}

All of our patients were admitted to the ICU immediately and second day post-operatively. The GCS worsened by $2^{\circ}$ in 2 patients of the tubular group (15 males + 3 females) due to increase in perifocal edema in spite of reduction of the size of hematoma in the follow-up CT. This deterioration continued on the second and third days till death. Three patients remained stationary for 5-7 days, one of them started to improve, and the other two started to deteriorate as a result of complications of being bed ridden till death after about 3 weeks from surgery. Thirteen patients started to improve on the first or second day post-operatively and continued this improvement till discharge from hospital after about 2-3 weeks and during the follow-up periods. Thus, the total mortality was 4 patients and 14 patients experienced different degrees of improvement: 3 patients were conscious with no deficits and good recovery, 9 patients were conscious with mild disability, and 2 patients were conscious with severe disability.

Patients (11 males +7 females) managed by stereotactic resection and thrombolysis of the hematomas were admitted to ICU the day of operation and 1 day after. Two patients experienced increased hematoma size due

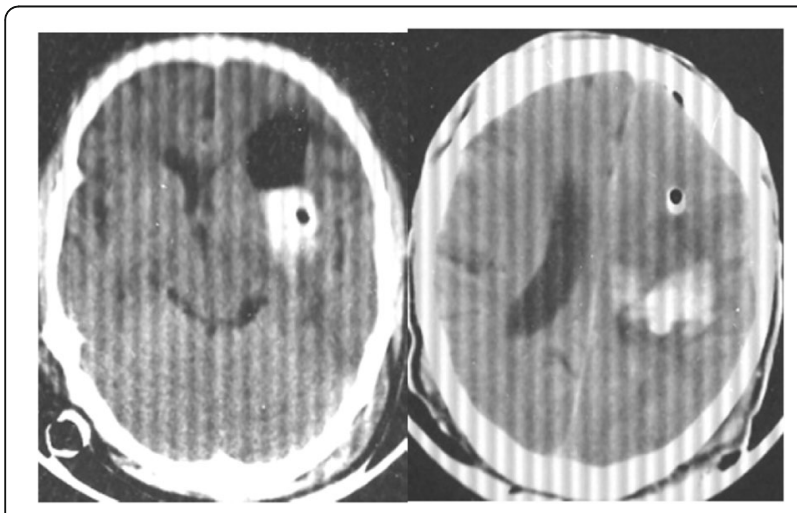

Fig. 8 Post-operative CT for intracerebral hematoma operated by tubular method to uncontrolled blood pressure and died 5-7 $\mathrm{h}$ post the procedures. Three patients did not improve and continued deterioration till death during the period of hospital stay (2-3 weeks) despite the reduction of the hematoma size. Thus, the final results in this group after the follow-up period were as follows: 5 patients died, 1 patient was conscious with severe disability, 10 patients were conscious with mild disability, and 2 patients were conscious with complete recovery.

The most striking observation in all patients under the study was the close relationship between the size of the hematoma and the outcome irrespective to the method of treatment, and this could be explained by increasing the secondary damage by toxic by-products of hemoglobin degradation, more elevation of intra cranial pressure, and reduction of the perfusion pressure with increasing the hematoma size.

Correlation between the GCS on admission and monthly for 6 months post-operatively was used to assess the outcome of surgical treatment.

\section{Discussion}

The devastating harmful effects of intracerebral hematoma $(\mathrm{ICH})$ on the brain result from increased intracranial pressure, local mechanical mass effect on surrounding brain, and toxic effect of blood degradation by-products with their effects on the neurons causing cell rupture and on blood vessels resulting in their vasospasm and secondary ischemic insults to the brain. Compared with conservative treatment (in which the hematoma disappears naturally over time), surgery has the advantage of evacuating the clot efficiently. Consequently, ICH removal is beneficial because it reduces not only the mechanical injury but also the level of chemical damage within the brain [9-11]. Roughly, the patients may get benefit from evacuation especially if the hematoma is large and surfacing. Open craniotomy for evacuation of the hematoma may not be applicable in some patients with uncontrolled blood pressure and bad general conditions that do not permit for general anesthesia. Recently, the advances in minimally invasive procedures give a good chance to treat such people earlier with minimal risk under local anesthesia with decreased tissue trauma and operative time and diminished blood loss $[5,8]$.

Some authors categorized the patients who could benefit from minimally invasive clot resection and thrombolysis to be either sexes, age of 30 to 80 years with superficial location, Glasgow Coma score more than 9, volume between 25 and $40 \mathrm{~mL}$, within $72 \mathrm{~h}$ of onset, and these specifications are largely matching with our patients under the study [12].

Recently, multiple tubular retractors have replaced the old flat ones and are used in multiple indications and 


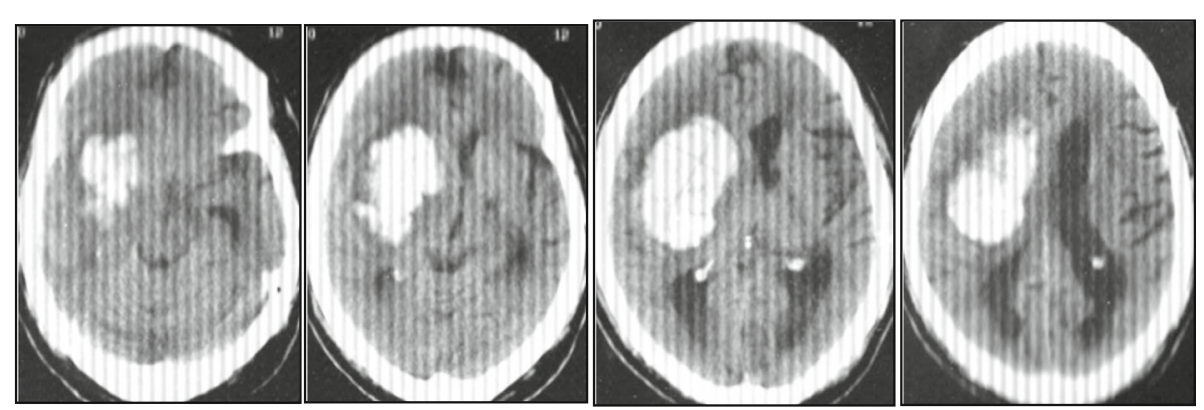

Fig. 9 Admission $C T$ scan

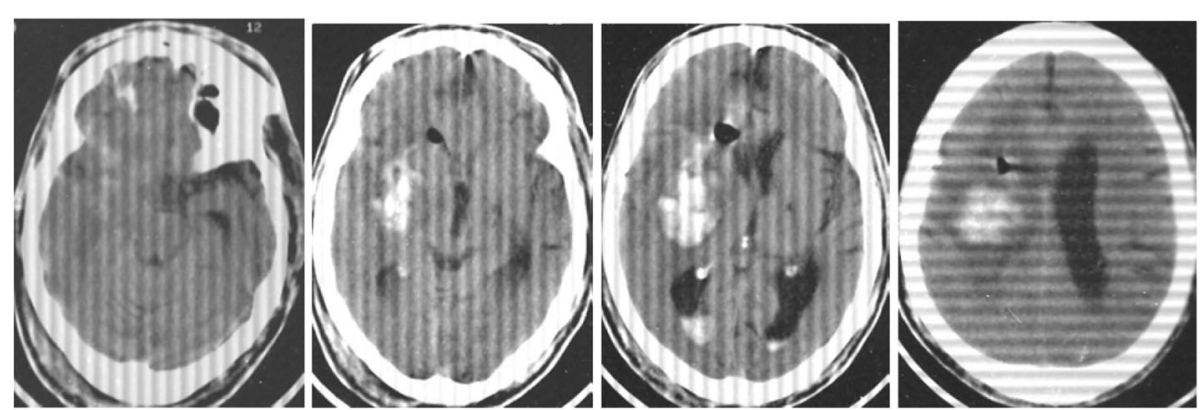

Fig. 10 Post-operative CT for intracerebral hematoma operated by stereotactic method
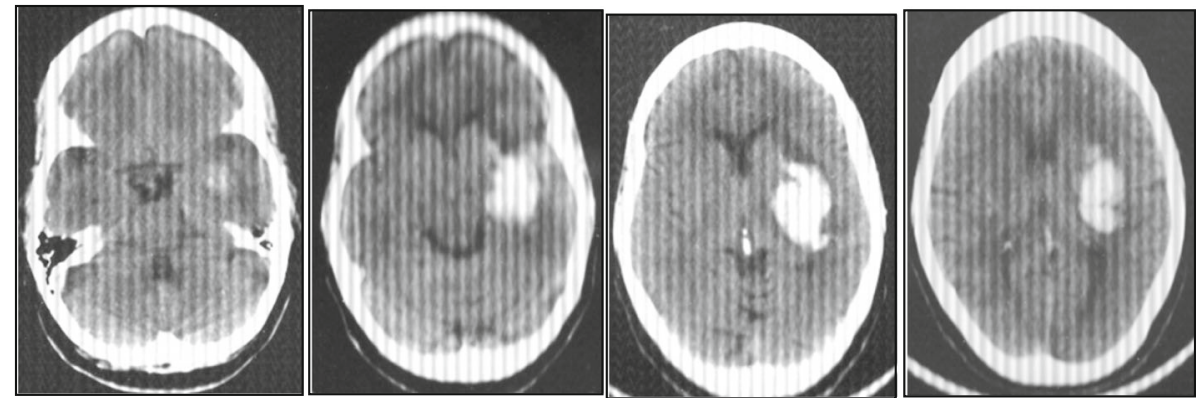

Fig. 11 Admission CT scan
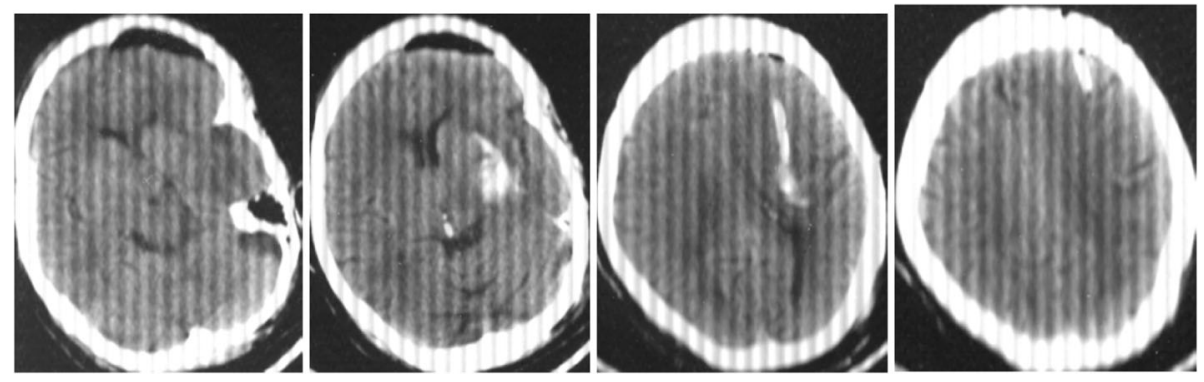

Fig. 12 Post-operative CT for intracerebral hematoma operated by stereotactic method 
approaches. These retractors have the advantages of being less traumatic to the brain tissue and allow a wide field for manipulating different lesions [13]. We used a modified retractor similar to the nasal speculum, and this type gave us all what we need to wash, coagulate, and resect the hematomas safely. The operative time in the tubular group was shorter than that in the stereotactic group.

Frame-based stereotaxy is the most accepted form of minimally invasive procedures used for resection of the hematoma [14]. In all of our cases, we started evacuation of the hematomas by gentle simple syringe aspiration to remove the fluid part of the hematoma and this was followed by handmade model of Archimedes screw insertion (made to be compatible with the used stereotaxy frame as regards the dimensions and diameters) for clot fragmentation and aspiration. Some authors put strict criteria for the catheter left in the hematoma and used for injection of clot lysing materials. These catheters should be in the center and run through the long axis of the clot to avoid reopening of the ruptured vessel causing rebleeding $[15,16]$.

Analysis of our results revealed total survival of $27 \mathrm{pa}-$ tients (out of 36) with different grades of recovery but most of the recovered patients (24) were totally independent with or without mild disability, and this is considered as a good achievement in treating an old-aged and risky group of patients with devastating and life-threatening pathology. From our experience, the grave behavior of the hypertensive intracerebral arterial rupture has its frustrating course. More than 20 candidates during our study were planned to have the maneuver and deteriorated before surgery, thus became unfit and got excluded. Another five patients suddenly died before intervention. Moreover, signing an informed consent by the patient relatives was not so easy due to the unguaranteed nature of the maneuver. Besides, lack of adequate scientific information among the treating physicians of internal medicine department in our institute regarding the maneuver aided more block. Hence, to avoid deterioration of patients, aspiration of the clot should be done as early as possible (fearing of increased risk of hematoma enlargement and rebleeding).

\section{Conclusions}

The two studied minimally invasive hematoma resection procedures have advantages of reducing time and amount of surgical stress, the possibility of being performed under local anesthesia, facility of earlier evacuation, and reduced tissue trauma. Performing the procedures under image monitoring may be helpful in anticipating and detecting intraoperative accidents. Stereotactic aspiration is still helpful in chronic stage, where the clot becomes liquefied and easy for simple aspiration. This makes rehabilitation easier and further deterioration avoidable.

\section{Availability of data and materials}

Data sharing is not applicable to this article as no datasets were generated or analyzed during the current study. Please contact the author for data requests.

\section{Author's contribution}

I am responsible for the study design, manuscript writing, etc. The author read and approved the final manuscript.

\section{Ethics approval and consent to participate}

All procedures performed in this study involving human participants were in accordance with the ethical standards of the Egyptian National Research Committee. The local ethical committee of the Alexandria Faculty of Medicine approved this study with approval reference number of (0303823) dated January 18, 2018.

Consent for participation is not applicable as this is a retrospective study.

\section{Consent for publication}

Informed consents for publication were obtained from all individual participants included in the study.

\section{Competing interests}

The authors declare that he have no competing interests.

\section{Publisher's Note}

Springer Nature remains neutral with regard to jurisdictional claims in published maps and institutional affiliations.

Received: 25 February 2018 Accepted: 8 July 2018

Published online: 31 August 2018

\section{References}

1. Carandang R, Seshadri S, Beiser A, et al. Trends in incidence, lifetime risk, severity, and 30-day mortality of stroke over the past 50 years. JAMA. 2006; 296:2939-46.

2. Flaherty $M L$, Haverbusch $M$, Sekar $P$, et al. Long-term mortality after intracerebral hemorrhage. Neurology. 2006;66:1182-6.

3. Gong Y, Tian H, Xi G, et al. Systemic zinc protoporphyrin administration reduces intracerebral hemorrhage-induced brain injury. Acta Neurochir Suppl. 2006;96:232-6.

4. Nakamura T, Keep RF, Hua Y, et al. Iron-induced oxidative brain injury after experimental intracerebral hemorrhage. Acta Neurochir Suppl. 2006; 96:194-8.

5. Nilsson OG, Lindgren $A$, Brandt $L$, et al. Prediction of death in patients with primary intracerebral hemorrhage: a prospective study of a defined population. J Neurosurg. 2002;97:531-6.

6. Van Asch CJ, Luitse MJ, Rinkel GJ, van der Tweel I, Algra A, Klijn CJ. Incidence, case fatality, and functional outcome of intracerebra haemorrhage over time, according to age, sex, and ethnic origin: a systematic review and meta-analysis. Lancet Neurol. 2010;9(2):167-76.

7. Carvi $Y$, Nievas MC, Haas $E$, Hollerhage $H G$, et al. Combined minimal invasive techniques in deep supratentorial intracerebral haematomas. Minim Invasive Neurosurg. 2004;47:294-8.

8. Nakano T, Ohkuma H, Ebina K, et al. Neuroendoscopic surgery for intracerebral haemorrhage-comparison with traditional therapies. Minim Invasive Neurosurg. 2003;46:278-83.

9. Etminan N, Beseoglu K, Turowski B, et al. Perfusion $\mathrm{CT}$ in patients with spontaneous lobar intracerebral hemorrhage: effect of surgery on perihemorrhagic perfusion. Stroke. 2012;43:759-63.

10. Perez de la Ossa N, Sobrino T, Silva $Y$, et al. Iron-related brain damage in patients with intracerebral hemorrhage. Stroke. 2010;41:810-3.

11. Staykov D, Wagner I, Volbers B, et al. Natural course of perihemorrhagic edema after intracerebral hemorrhage. Stroke. 2011;42:2625-9.

12. Zhou X, Chen J, Li Q, Ren G, Yao G, Liu M, Dong Q, Guo J, Li L, Guo J, Xie P. Minimally invasive surgery for spontaneous supratentorial intracerebral hemorrhage: a meta-analysis of randomized controlled trials. Stroke Nov. 2012;43(11):2923-30 
13. Greenfield JP, Cobb WS, Tsouris AJ, Schwartz TH. Stereotactic minimally invasive tubular retractor system for deep brain lesions. Neurosurgery. 2008; 63(ONS Suppl 2):ONS 334-40

14. Mohadjer M, Braus DF, Myers A. CT-stereotactic fibrinolysis of spontaneous intracerebral hematoma. Neurosurg Rev. 1992;15:105-10.

15. Gaberel T, Magheru C, Emery E. Management of non-traumatic intraventricular hemorrhage. Neurosurg Rev. 2012;35:485-94.

16. Morgan T, Zuccarello M, Narayan R, et al. Preliminary findings of the minimally-invasive surgery plus rtPA for intracerebral hemorrhage evacuation (MISTIE) clinical trial. Acta Neurochir Suppl. 2008;105:147-51.

\section{Submit your manuscript to a SpringerOpen ${ }^{\mathcal{O}}$} journal and benefit from:

- Convenient online submission

- Rigorous peer review

- Open access: articles freely available online

High visibility within the field

- Retaining the copyright to your article

Submit your next manuscript at $\boldsymbol{\nabla}$ springeropen.com 